\title{
Variations
}

Variations

Revue internationale de théorie critique

$8 \mid 2006$

Subjectivités libres et critique de la répression

\section{Subjectivités libres et critique de la répression}

Éditorial

\section{CpenEdition}

\section{Journals}

Édition électronique

URL : http://journals.openedition.org/variations/495

DOI : 10.4000/variations.495

ISSN : 1968-3960

Éditeur

Les amis de Variations

Édition imprimée

Date de publication : 1 novembre 2006

Référence électronique

"Subjectivités libres et critique de la répression », Variations [En ligne], 8 | 2006, mis en ligne le 27 décembre 2012, consulté le 22 septembre 2020. URL : http://journals.openedition.org/variations/495 DOI : https://doi.org/10.4000/variations.495

Ce document a été généré automatiquement le 22 septembre 2020

Les ami•e•s de Variations 


\title{
Subjectivités libres et critique de la répression
}

\author{
Éditorial
}

1 Nous sommes envahis. Aucun maquis, nulle fréquence de Radio Londres pour prendre la tangente. Envahis par un discours anxiogène, fataliste et répressif, qui veut justifier le dressage des enfants, le matraquage des lycéens, la domination des banlieusards, l'expulsion des immigrés, la persécution des précaires, la criminalisation du mouvement social. Ce discours voudrait enfermer dans des centres militaires la violence diffuse et massive qui s'inscrit dans les relations sociales d'une société postcoloniale autoritaire. Il s'agirait de ficher les plus petits, selon une définition de la déviance digne des manuels soviétiques d'avant Khrouchtchev. On voudrait réglementer la psychanalyse selon des normes psychiatriques qui semblent tout ignorer de la percée conceptuelle ouverte par Freud. À la répression policière et aux lois d'exception s'ajoute ainsi une répression des esprits, relayée par les mass media, allant à l'encontre de tout ce qui pourrait permettre une expérience de soi autonome. Raison pour laquelle nous avançons la subjectivité libre comme référence alternative à la vision répressive, au sein de ce numéro qui a été coordonné par Alex Neumann et Lucia Sagradini. La subjectivité libre peut ici s'entendre comme freie Entfaltung, expression évoquant le déploiement des pétales d'une fleur.

2 En l'absence d'un projet émancipateur clairement nommé, et en face de professionnels de la politique dont l'horizon se limite à «l'ordre républicain », plusieurs appels publics tentent de conjurer la puissance corrosive de la répression. Des milliers de citoyens se sont prononcés contre le contrôle administratif des enfants trouble-fête voulu par le ministre de l'Intérieur, réclament l'amnistie des jeunes révoltés de l'hiver 2005 et du printemps 2006, manifestent leur volonté de s'inscrire sur les listes électorales pour disposer d'une réplique élémentaire, marquent leur soutien aux sans-papiers... Ces appels ne sont pas impuissants, ils arrivent à calmer la tempête punitive qui s'est emparée du pouvoir, mais ils restent nécessairement cantonnés à la défensive. La critique des excès répressifs ne dit pas que la répression est tolérée, sinon attendue, par un grand nombre de personnes qui ne connaissent pas d'autres réponses et qui se sentent rassurées par le rappel des rapports d'autorité, à droite comme à gauche. Tel 
est le sens des études sur la personnalité autoritaire, présentées par Adorno il y a plus de cinquante ans. En revanche, l'expérience de la liberté, même si elle reste partielle ou éphémère, rend les individus résistants et détruit la puissance de la publicité autoritaire. Variations participe à sa manière au développement d'un espace public oppositionnel, face à la représentation répressive, en proposant d'avancer vers une compréhension globalisante de ces phénomènes, grâce au recours à des concepts forgés par la Théorie critique et le freudo-marxisme. Les articles de ce numéro abordent l'enfance sans entraves, la jeunesse en révolte, la prise de parole des salariés, la résistance aux abstractions totalitaires, le cri de négativité des zapatistes et leur refus de s'identifier à un monde fait de guerres et de carcans.

Oskar Negt, auteur majeur de la Théorie critique et fondateur de la Glockseeschule, renverse la table de l'École traditionnelle, en abordant les promesses tenues de la pédagogie alternative. Il met en relief les relations de réciprocité entre la proximité corporelle, la levée des inhibitions et l'autonomie des enfants. Alain Bertho saisit la révolte des banlieues comme un moment de crise propice au lancement d'un chantier de recherche anthropologique, pouvant inspirer une critique politique. Il amorce le dépassement des cadres d'interprétation positivistes, durkheimiens et marxistesléninistes, qui cherchent tous à éclairer la subjectivité à partir d'une position d'extériorité aux acteurs. Le communisme municipal français, que l'auteur a longuement exploré, est lui aussi soumis à une déconstruction analytique. Alex Neumann entame une démarche similaire, qu'il illustre par la prise de parole des salariés. Il préconise l'écoute sociologique à la place des monologues académiques. Les soubassements conceptuels de ce projet proviennent d'un héritage délaissé de la Théorie critique, qu'il s'efforce de mettre à jour, afin d'interroger la sociologie explicative. Bourdieu ne pensait-il pas que les ouvriers ne savent pas parler? Lucia Sagradini investit les brèches et fissures des appareils répressifs, en montrant les chemins détournés par lesquels Winston Smith, protagoniste du roman 1984, arrive à se réapproprier son autobiographie en dépit du mensonge totalitaire. L'appareil du parti, s'exhibant comme une entité toute-puissante, s'avère être une construction précaire, dès lors que l'adhésion subjective vient à lui manquer. Soizic Bonvarlet accorde de belles pages au souvenir de l'enfance berlinoise de Walter Benjamin, poète, philosophe et refuznik. Manière de dire que la mélancolie et la rêverie sont des refuges indispensables, au vu de la modernité cynique qui nous assaille, et que nulle pilule psychotropique ne saurait dissoudre. John Holloway, altermondialiste, zapatiste et théoricien de la révolution, nous accorde un entretien dans lequel il reprend l'idée d'un refus radical du monde tel qu'il se donne, inspirée de la dialectique négative d'Adorno. L'Autre campagne du sous-commandant Marcos est discutée à partir de cet angle décalé. Fernando Matamoros, dont les écrits sur l'utopie au Mexique sont déjà connus par le public français, approfondit cette réflexion en puisant dans les ressources de l'imaginaire indigène et des cultures de la rébellion. Le trône des vainqueurs de l'histoire vacille et le fait accompli menace d'être renversé à tout moment.

Hors-champ, deux articles conspuent le discours conservateur de la valeur-travail. Stephen Bouquin rend hommage à Jean-Marie Vincent (1934-2004), fondateur de notre revue, en soulignant son apport conceptuel à la sociologie contemporaine. Il insiste sur l'originalité du concept de travail abstrait, issu de la pensée de Marx, et qui signale les transformations du travail sous les conditions de la socialisation marchande. Le texte est issu d'un colloque organisé par l'Université Paris 8 et par Variations. Philippe Maingault constate pour sa part que le mouvement contre le Contrat Première 
Embauche s'est accompagné, entre autres choses, d'une idéalisation implicite du Contrat à Durée Indéterminée, dont les contraintes avaient pourtant été contestées par des luttes sociales au cours des années soixante et soixante-dix. Le numéro s'achève en point d'orgue sur un entretien avec Denis Berger et Michel Lequenne, qui permet de passer en revue les riches expériences politiques et théoriques des deux intellectuels communistes, formés par le trotskisme critique, le surréalisme et d'autres expériences vivantes. Loin de renier leur engagement initial, ils se disent repoussés par le sectarisme actuel de la Ligue communiste révolutionnaire, rappelant en cela le parcours de Jean-Marie Vincent.

5 Variations prend également date pour le Congrès Marx International V - qui se tiendra du 3 au 6 octobre 2007 à l'Université de Nanterre - et dont elle est l'une des revues coorganisatrices. À cette occasion, nous entendons favoriser le débat contemporain sur la Théorie critique, à partir du thème du congrès " Anticapitalisme et altermondialisme ». La revue préparera un numéro spécial à cette occasion (automne 2007). En attendant, nous lançons un appel à communication pour notre numéro de printemps 2007, qui interroge les Frontières de la politique. 